\title{
Words matter: the prevalence of chiropractic-specific terminology on Australian chiropractors' websites
}

Kenneth J. Young

\begin{abstract}
Background: Chiropractors use words and phrases in unique ways to express traditional, chiropractic-specific theories. This lexicon represents concepts that reinforce the separation of chiropractic from other health care professions. It may impact referrals both to and from chiropractors, lead to public confusion about health care issues, and reduce cross-disciplinary research. Therefore, it is important to understand how prevalent chiropracticspecific terms are in publicly available media.

Methods: Five chiropractic terms were selected: subluxation, adjustment, vital (-ism/-istic), wellness, and Innate (Intelligence). States and territories in Australia were proportionately sampled according to population of chiropractors using a Google search for chiropractors' private practice websites. The top results were recorded. Websites were word-searched on every publicly available page for the five terms. Context was checked to count only terms that were used to support a chiropractic-specific concepts. The number of occurrences of each term was recorded, tallied nationally and by state/territory. Descriptive statistics were applied to determine prevalence.
\end{abstract}

Results: Three hundred sixty-nine websites were sampled, based on an estimate of 5500 chiropractors practising in Australia. Nationally, $85 \%$ of chiropractors used one or more terms. The term adjust (-ing/-ment) occurred most frequently, being found on 283 websites (77\%) with a total of 2249 occurrences. Wellness was found on 199 websites (54\%) with 872 occurrences; subluxation was found on 104 websites (28\%), 489 occurrences; vital (-ism/ -istic) on 71 websites (19\%) with 158 occurrences; and Innate was least used, being found on 39 websites (11\%) with 137 occurrences.

Conclusion: A majority of the Australian chiropractors sampled used one or more chiropractic-specific terms on their websites. Future research should explore the effects of chiropractic language on the public, policy-makers, and other health care professionals.

Keywords: Chiropractic, Language, Cultural authority, Evidence-based practice

\section{Background}

Use of a common language is essential to mutual understanding. This sentiment has been noted in a variety of fields, from dance education to corporate governance to disability, and more [1-5]. The chiropractic profession

\section{Correspondence: kjyoung1@uclan.ac.uk}

School of Sport and Health Sciences, University of Central Lancashire, Preston PR1 2HE, England

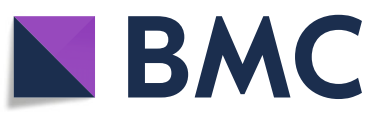

uses words and phrases in a unique way to express traditional chiropractic-specific theories and concepts $[6,7]$. This lexicon reinforces the separation of chiropractic from other health care professions $[8,9]$. Promoting chiropractic as alternative rather than complementary or mainstream may be detrimental to patients by deterring or delaying referrals both to and from other health care professionals [10-14]. Barker, Reid, and Lowe [15] listed

(c) The Author(s). 2020 Open Access This article is licensed under a Creative Commons Attribution 4.0 International License, which permits use, sharing, adaptation, distribution and reproduction in any medium or format, as long as you give appropriate credit to the original author(s) and the source, provide a link to the Creative Commons licence, and indicate if changes were made. The images or other third party material in this article are included in the article's Creative Commons licence, unless indicated otherwise in a credit line to the material. If material is not included in the article's Creative Commons licence and your intended use is not permitted by statutory regulation or exceeds the permitted use, you will need to obtain permission directly from the copyright holder. To view a copy of this licence, visit http://creativecommons.org/licenses/by/4.0/ The Creative Commons Public Domain Dedication waiver (http://creativecommons.org/publicdomain/zero/1.0/) applies to the data made available in this article, unless otherwise stated in a credit line to the data. 
three different reasons common language was important when communicating information about back pain: 1) patients seeking information from health care professionals may encounter difficulty interpreting health care literature, 2) misunderstandings may arise among health professionals, and 3) a lack of standard definitions can make comparison of research studies challenging. Lawrence noted that semantic incompatibilities have hampered intraprofessional development of chiropractic as well [16]. Authors have called for the abandonment of traditional, uniquely chiropractic language [17]. Therefore, it may be useful to learn how prevalent chiropractic-specific terms are in publicly available advertising media, such as websites. Five terms stood out in the chief investigator/author's opinion as likely to express uniquely chiropractic concepts. They were: subluxation, adjust (-ing/-ment), vital (-ism/-istic), wellness, and Innate (Intelligence). Subluxation and adjustment have been shown to be prevalent in chiropractic literature [18].

\section{Subluxation}

Subluxation is a term used in medicine to denote a partial dislocation, a significant injury to a joint, involving damage to soft tissues and possibly articular cartilage and bone [19]. In chiropractic the definition is different, indicating a tiny displacement of one bone in relation to another, possibly affecting the function of a nearby nerve or nerves [20]. The chiropractic version has no profession-wide agreement, has poor inter- and intraobserver reliability, and is sometimes claimed, with little evidence, to cause a wide range of diseases [21].

Several papers in recent years have examined the prevalence and use of the word subluxation by chiropractors. In 2019, Marcon, Murdoch, and Caulfield studied Alberta, Canada [22]. They found that 121 clinic websites (33\%) presented a theory for chiropractic subluxation and claimed wide-ranging health benefits from its removal. In 2018, Funk, et al. gathered data from 46 chiropractic courses around the world and tallied the number of instances of the word subluxation in course/ unit/module titles and descriptions but did not analyse the context [23]. So even websites that used the term in a non-positive sense, for example to dissociate themselves from that line of thinking, were counted in the study even though the meaning of the term was not being used to support or advocate traditional chiropractic concepts. Funk's study counted the word subluxation no matter in what context it was used. For instance, 'We practice subluxation-based chiropractic' and 'We believe subluxation is a historical concept only' would both have been counted. This paper followed on from a 2011 study by Mirtz and Perle which examined course/unit/module descriptors in North American chiropractic teaching institutions [24]. The latter study found an increase in the mean incidence of the term, rising from 5.53 in the first study to 6.50 in the follow-up at the North American Institutions. Funk found lower incidence of the 'subluxation' outside North America (mean of 0.83) [23].

\section{Adjust (-ing/-ment)}

The use of a chiropractic-specific meaning of adjust originates with DD Palmer: "The science of chiropractic has led to the creation of the art of vertebral adjusting." [25] The Cambridge English dictionary defines adjustment as, "a slight change made to something to make it fit, work better, or be more suitable" [26]. Mirriam-Webster online offers as one of its definitions a specific chiropractic variant: "the manual or mechanical manipulation of a joint (especially the spine) in which a controlled force is applied to the joint" [27]. Mirriam-Webster also provides a specific medical definition of manipulate: "to examine or treat by skilful use of the hands, as in palpation, reduction of dislocations, or changing the position of a fetus [sic]" [28]. Therefore, adjustment as used by chiropractors in relation to treatment is a chiropracticspecific term, while the more generic or mainstream term for manually-induced motion of bones and joints used by other health professions is manipulation.

\section{Vital(-ism/-istic)}

Vitalism is not a chiropractic concept per se, but some chiropractors employ a vitalistic paradigm to describe the benefits of chiropractic [29-32]. Sociologist Holly Folk noted that vitalism was found in many alternative nineteenth century health care occupations, but that it has survived in chiropractic [33]. Vitalism is not a concept employed by the medical profession, and it is also not found in chiropractic accreditation education standards [34]. Although there are multiple definitions of vitalism, chiropractors do not adhere to one. Some chiropractors specifically refer to Innate Intelligence, a vitalistic concept, but even this version of vitalism has had multiple definitions. Keating noted that it was a synonym for homeostasis, a label for our ignorance, an "explanation" for as yet poorly understood phenomena, and a metaphysical premise [35]. However many chiropractors only vaguely refer to concepts of a life- or health-giving force $[31,35,36]$. As an entity that is not able to be objectively and directly measurable, it is untestable and therefore not amenable to scientific methods of investigation [37-39]. Use of this term and the concept it represents may result in chiropractic being viewed as an alternative rather than complementary form of health care, thus separating it from the mainstream. 


\section{Wellness}

Like vital(-ism/-istic), wellness is not a chiropracticspecific term. While some chiropractors use it in the mainstream way to address public health functions like promoting healthy behaviours (e.g. stop smoking, reduce alcohol consumption), others use it to imply chiropractic-specific benefits theorised to derive from subluxation removal [40-45]. Studies have found that chiropractic wellness-oriented practices tend to overtreat patients and are more likely to have aggressive marketing tactics $[46,47]$. In addition, one study has found that chiropractors that practice with a wellness model receive fewer referrals from medical doctors [48].

\section{Innate (intelligence)}

This term was coined by DD Palmer, although it has had several definitions $[35,49]$. It is essentially the chiropractic representation of vitalism, and like vitalism, it is often vaguely referred to by chiropractors as an energy- or health-restoring force [50-54]. Its chiropractic uniqueness and metaphysical connotations contribute to chiropractic as separate and somehow different from mainstream health care; some authors also believe it is divisive within chiropractic [38].

The purpose of this paper is to document the prevalence of these five terms on chiropractors' websites in Australia when they were used to convey or support chiropractic-specific concepts.

\section{Methods}

Sample size was calculated using the Centers for Disease Control tool, Epi Info [55]. The calculations assumed 5500 chiropractors practising in Australia, as well as an expected frequency of $50 \%$, that is, we expected $50 \%$ of web sites to contain at least one chiropractic term. A minimum sample of 359 was calculated to provide a $95 \%$ confidence interval with a $5 \%$ margin of error. Each state/territory was proportionately sampled according to population of chiropractors. The proportion was obtained from the Chiropractic Board of Australia (2108) [56]. Only private practice websites were included, not organisations or educational institutions. We employed the use of the Google search engine to evaluate practicebased websites using the term "chiro" + [name of state or territory] for each state and territory. For instance, we searched for chiro+New South Wales. This resulted in a list of chiropractors' web sites. We then copied and pasted the URL of the main web page into a Microsoft Excel spreadsheet, starting from the top of each set of results until the required number for that state or territory was collected. For instance, only $1.3 \%$ of chiropractors practice in the Australian Capital Territory, which translated to 5 web sites, so the URLs of top 5 websites returned by the Google search were recorded. Then each web site was visited and word-searched on every available page for each of the five terms.

Context was checked to ensure a positive chiropractic meaning for each use of a term. That is, in order to be counted, the term needed to denote a chiropracticspecific context in a positive way. A hypothetical example of a positive meaning is: "We alleviate vertebral subluxations to enhance your health". An example of a non-positive meaning is: "We view the subluxation concept as historical rather than clinically meaningful". Positive uses were recorded; non-positive uses were not, because they did not advocate chiropractic uniqueness or separateness. A statement indicating that chiropractic adjustments could directly enhance wellness would have been counted for both the terms adjustment and wellness, as the context denotes a positive, chiropracticspecific meaning. However, the generic use of a term would not, such as: "We believe that your wellness is enhanced when you experience less pain."

Research assistants were trained in two meetings during which several random chiropractic clinic websites were accessed and the terms found therein discussed among the group, so all reached agreement on positive uses of terms to be recorded, and that negative uses of terms would not be recorded. If a website had both positively-used terms and non-positively-used terms, only the positively-used ones were counted. The research assistants divided the states and territories among themselves and recorded the number of occurrences of each term on the spreadsheet. The chief investigator randomly sampled about $5 \%$ of the results submitted by the research assistants to ensure accuracy. No errors or omissions were found. The chief investigator then used Excel mathematical functions to add up the occurrences as well as to determine percentages when compared to the number of practising chiropractors. This gave the prevalence of occurrences by state/territory as well as nationally both by the total number of occurrences of terms and number of practices that used any term at least once.

\section{Results}

Three hundred sixty-nine websites were sampled according to the proportions provided by the Chiropractic Board of Australia. Due to minor errors in data collection, some states/territories were slightly oversampled, others slightly undersampled, however the overall national sample was achieved to reach the desired 95\% confidence with 5\% margin of error. See Table 1.

All occurrences of each term were tallied for each state and territory. Adjust(-ing/-ment) was the most commonly occurring term at 2249 total occurrences nationwide, followed by wellness at 872 , subluxation at 489 , 
Table 1 Websites sampled, based on 5500 chiropractors in Australia

\begin{tabular}{|c|c|c|c|}
\hline $\begin{array}{l}\text { State/ } \\
\text { Territory }\end{array}$ & $\begin{array}{l}\text { Percent of chiropractors according to } \\
\text { CBA }\end{array}$ & $\begin{array}{l}\text { Proportionate number to sample according to CBA } \\
\text { percentage }\end{array}$ & $\begin{array}{l}\text { Number actually } \\
\text { sampled }\end{array}$ \\
\hline ACT & 1.3 & 5 & 5 \\
\hline NSW & 33.5 & 124 & 96 \\
\hline NT & 0.5 & 2 & 10 \\
\hline QLD & 16.0 & 59 & 56 \\
\hline SA & 7.0 & 26 & 33 \\
\hline TAS & 1.0 & 4 & 24 \\
\hline VIC & 25.9 & 96 & 93 \\
\hline WA & 11.8 & 44 & 52 \\
\hline TOTAL & $97^{a}$ & 360 & 369 \\
\hline
\end{tabular}

Legend: CBA Chiropractic Board of Australia, the registration agency, ACT Australian Capital Territory, NSW New South Wales, NT Northern Territory, QLD Queensland, SA South Australia, TAS Tasmania, VIC Victoria, WA Western Australia

* $3 \%$ of chiropractors did not disclose a principal place of practice to the CBA

$\operatorname{vital}(-\mathrm{ism} /$-istic) at 158, and Innate at 137. See Table 2 for findings from each state and territory.

$85 \%$ of Australian chiropractic websites use one or more chiropractic-specific terms. Nationwide, adjust(-ing/-ment) was most common with 283 (77\%) websites using the term at least once, followed by wellness at 199 (33\%), subluxation at $104(28 \%), \operatorname{vital}(-\mathrm{ism} /-$ istic $)$ at 71 (19\%), and Innate at 39 (11\%). See Table 3.

\section{Discussion}

While any profession will have some amount of profession-specific terminology, chiropractic falls within the larger realm of health care professions, all of which should reasonably be expected to use a common terminology. $85 \%$ of Australian chiropractic websites sampled used one or more chiropractic-specific terms, representing chiropractic-specific concepts, would seem to indicate that a majority of Australian chiropractors view themselves as providing a service that is different to that of other health practitioners. Non-evidence-based beliefs have been found in Australian chiropractic students as well as in practitioners in other countries [57-60]. Since a variety of practitioners may provide manual therapy including manipulation, it is likely that this view is maintained by a combination of the persistence of traditional chiropractic beliefs like nerve interference, postural correction, etc., and deference to chiropractic history, taught in schools and seminars, and tolerated by regulatory bodies.

Since terms tended to occur multiple times when they appeared on any website, it was thought that the most useful metric would be the number of websites that mentioned any term any number of times. This represents the prevalence of chiropractic-specific terminology in the chiropractic community overall more accurately than the total number of times terms occurred.

$77 \%$ of Australian chiropractors were found to use the term adjustment rather than the more generic manipulation. Unless there is something unusual about a chiropractic adjustment, some method or effect that is different from a manipulation delivered by a physiotherapist or osteopath, then there is no need for a different term. Some chiropractors argue that it is, in fact, different, that a chiropractic adjustment is specific and/or

Table 2 All occurrences of each term by state/territory

\begin{tabular}{|c|c|c|c|c|c|c|}
\hline State/ Territory & Subluxation & Vital(-ism/-istic) & Wellness & Innate & Adjust(-ing/-ment) & Totals \\
\hline$A C T$ & 15 & 0 & 6 & 0 & 29 & 50 \\
\hline NSW & 129 & 64 & 275 & 17 & 431 & 916 \\
\hline NT & 44 & 9 & 8 & 1 & 62 & 124 \\
\hline QLD & 83 & 23 & 255 & 9 & 712 & 1082 \\
\hline SA & 97 & 21 & 85 & 14 & 330 & 547 \\
\hline TAS & 9 & 14 & 35 & 49 & 96 & 203 \\
\hline VIC & 83 & 20 & 158 & 46 & 337 & 644 \\
\hline WA & 29 & 7 & 50 & 1 & 252 & 339 \\
\hline TOTAL & 489 & 158 & 872 & 137 & 2249 & 3905 \\
\hline
\end{tabular}

Legend: These numbers include multiple occurrences on each website. When a term was found on a website, it tended to be used multiple times 
Table 3 Numbers of websites with any occurrence of the chiropractic-specific terms, n (\%)

\begin{tabular}{|c|c|c|c|c|c|c|c|}
\hline $\begin{array}{l}\text { State/ } \\
\text { Territory }\end{array}$ & $\begin{array}{l}\text { Subluxation } \\
\text { n (\%) }\end{array}$ & $\begin{array}{l}\text { Vital (-ism/ } \\
\text {-istic) } \\
\mathrm{n}(\%)\end{array}$ & $\begin{array}{l}\text { Wellness } \\
\mathrm{n}(\%)\end{array}$ & $\begin{array}{l}\text { Innate } \\
\mathrm{n}(\%)\end{array}$ & $\begin{array}{l}\text { Adjust (-ing/- } \\
\text { ment) } \\
\mathrm{n}(\%)\end{array}$ & $\begin{array}{l}\text { Total websites with occurrence of any } \\
\text { term } \\
\mathrm{n}(\%)\end{array}$ & $\begin{array}{l}\text { Number of websites } \\
\text { sampled }\end{array}$ \\
\hline $\mathrm{ACT}$ & $3(60)$ & $0(0)$ & $2(40)$ & $0(0)$ & $5(100)$ & $5(100)$ & 5 \\
\hline NSW & $26(27)$ & $30(31)$ & $55(57)$ & $\begin{array}{l}16 \\
(17)\end{array}$ & $71(74)$ & $82(85)$ & 96 \\
\hline NT & $4(40)$ & $4(40)$ & $5(50)$ & $1(10)$ & $10(10)$ & $10(100)$ & 10 \\
\hline QLD & $17(30)$ & $12(21)$ & $40(50)$ & $5(9)$ & $49(88)$ & $51(91)$ & 56 \\
\hline SA & $12(36)$ & $10(30)$ & $20(71)$ & $8(24)$ & $29(88)$ & $31(94)$ & 33 \\
\hline TAS & $6(25)$ & $3(13)$ & $11(61)$ & $2(8)$ & $17(71)$ & $20(83)$ & 24 \\
\hline VIC & $25(27)$ & $10(11)$ & $49(46)$ & $6(6)$ & $62(67)$ & $74(80)$ & 93 \\
\hline WA & $11(21)$ & $2(4)$ & $17(53)$ & $1(2)$ & $40(77)$ & $42(81)$ & 52 \\
\hline TOTAL & $104(28)$ & $71(19)$ & $\begin{array}{l}199 \\
(33)\end{array}$ & $\begin{array}{l}39 \\
(11)\end{array}$ & $283(77)$ & $315(85)$ & 369 \\
\hline
\end{tabular}

Legend: Whether a website mentioned a term one time or many, it was counted once for this table.

provides neurological/organic effects absent in the manipulations of other health care professionals [61-63]. However, there is little evidence of either specificity [64-68] or unique neurological/organic effects [69-72]. Therefore, there is little need for a chiropractic-specific term for manipulative therapy.

Strong emphasis on adjustment reduces chiropractic from a healthcare profession with a the broad range of diagnostic and therapeutic capabilities to a single therapeutic intervention. Chiropractors can provide various types of therapy, excluding drugs and surgery, but including expert advice on positive lifestyle changes [73]. Spinal manipulation is merely one tool in a large and diverse tool box that includes soft tissue therapy, rehabilitation techniques, patient education, exercise, and more. Chiropractors also receive considerable training in diagnosis [74]; the ability to differentiate an organic/pathological disorder that presents as musculoskeletal pain from a genuinely musculoskeletal disorder amenable to manual therapy should not be underestimated as a defining characteristic of the profession. It could be emphasised to administrators and policy-makers as a way to help them reduce the burden of musculoskeletal disorders on health care systems, whether governmental or private. The cost-effectiveness of using musculoskeletal experts in triage and treatment positions is now being recognised in the United Kingdom (UK), but physiotherapists are being awarded the First Contact Practitioner posts within the National Health Service [75].

The results for the terms subluxation, vital(-ism/ -istic), and Innate mean that some Australian chiropractors publicly espouse terms that represent an alternative view of the mechanism of health and disease. This representation of anti-science separates chiropractic from mainstream health care, yet many within chiropractic would like to be viewed as mainstream and scientific $[76,77]$. Codification of subluxation theory in American Medicare law has undoubtedly contributed to its perception by some as mainstream [13].

It would seem to require tolerance of cognitive dissonance to hold both scientific and vitalistic ideas at the same time. This has been found in at least one study [78]. Cognitive dissonance is a feeling of discomfort from maintaining two ideas simultaneously, both of which cannot be correct. For instance, it cannot be true that chiropractic adjustments to relieve vertebral subluxations are the key to maintaining health while so many people around the world who have never seen a chiropractor are living in perfect health. It seems unlikely that non-chiropractors, whether health professionals, representatives of the media, or lay public would tolerate such internal mental conflict so well.

The use of unique terms also allows detractors to generalise these concepts to all chiropractors [76, 7981]. It has even been shown to prompt people to question the validity of complementary medicine altogether [79]. As noted previously, the presence of an alternative paradigm of health is divisive within chiropractic as well $[24,38,82]$.

Wellness is probably the weakest term as regards chiropractic specificity. Chiropractors may use it in a profession-specific context, referring to the power of the adjustment in restoring health. In these circumstances, the term may be used in conjunction with the word chiropractic (e.g. "We promote chiropractic wellness," or "We practice wellness chiropractic.") [45] But wellness is a commonly-encountered term that is used in promoting public health initiatives such as stress reduction or moderation in alcohol intake, and thus wellness has a mainstream usage unrelated to chiropractic, as well. However, its use by chiropractors denoting broad effects 
to chiropractic treatment beyond pain relief and the improvement in quality-of-life that pain-reduced or painfree daily activities provides, further indicates the selfseparation of some chiropractors from mainstream health care.

Nelson, et al. noted the lack of cultural authority demonstrated by chiropractic because of the lack of scientific coherence in the unique chiropractic theories [83]. Similarly, lack of moral authority because of traditional beliefs persistent in homeopathy have threatened public funding and perceptions of legitimacy in that profession [84, 85]. Diversity in chiropractic care has been found to deter referrals from other professions to chiropractors and to be a source of internal conflict $[10,80]$. Student populations at different educational institution have been found to use different lexicons, either more scientific or more traditional, depending on the institution, so tolerance for diversity in education seems to contribute to division as well [86].

Unique terminology and concepts also have a negative effect on research. If diagnostic methods, treatment effects, and outcome measures are not agreed among health care professions, little cross-professional investigation can be undertaken, as Johnson suggests would benefit patients as well as the profession of chiropractic [87]. Veziari et al. investigated barriers to research in complementary and alternative medicine (CAM) professions, separating them into two broad categories, capacity and culture [88]. Capacity included access, competency, bias, incentives and time. Culture included values and the complex system of CAM. Language/terminology would logically fall within culture but was not specifically investigated in the study.

Unique terminology and the non-evidence-based beliefs it represents are ongoing issues for the chiropractic profession, and solutions have been proposed. Nelson [83] as well as French, Downie, and Walker recommended abandonment of traditional chiropractic beliefs and adoption of a model for the profession centred on evidence-based spine care [89]. Triano et al. developed a plan in 2010, focusing on improving educational quality and integration with other health professions [90]. Johnson et al. noted that chiropractic was well-placed to take a greater role in public health issues [91]. Murphy et al. cited the mainstreaming of podiatry as an example and suggested that chiropractic adopt the key characteristics that helped that profession gain legitimacy and integration. They were: become involved in public health, reform education, acquire hospital-based residencies, establish a clear identity, and ensure fidelity to the social contract [92].

\section{Strengths}

This study improves on previous studies of this type by searching for multiple chiropractic-specific terms, thus capturing a broader representation of uniquely chiropractic concepts. In addition, terms were examined to ensure that they were positively representing those concepts. 95\% confidence interval was achieved with 5\% margin of error.

\section{Limitations}

Google results are not random and favour clinics that are more skilled with marketing; this may have affected the results, but in an unknown way. This was an Australian study, so the results cannot be generalised throughout the world, as other chiropractic communities may hold different values. There are various ways of expressing these ideas search and limiting the search to five terms means that it is likely that not all clinics expressing chiropractic-specific concepts were captured. There have been increased efforts at compliance with advertising standards in Australia in the past few years [93] and this may have led some chiropractors not to abandon their beliefs but rather to mask their expression of them to adhere to CBA standards; therefore, chiropracticspecific ideas held by practitioners may be underrepresented in this study. Not every registered chiropractor has a website; some may work in a group practice with a group website; some may only use social media; some may not be represented on the internet at all, so some chiropractors may have been excluded from sampling. Thus, the results may not be generalisable to the chiropractor population of Australia. Only one research assistant made judgments on the websites in their assigned state or territory, so some terms may have been misinterpreted.

\section{Conclusion}

A majority of the Australian chiropractors sampled used one or more chiropractic-specific terms on their websites. Future research should explore the effects of chiropractic language on the public, policy-makers, and other health care professionals. Given the apparent detrimental effects, chiropractic should consider abandoning unique language.

\footnotetext{
Acknowledgments

The author would like to thank Murdoch University Chiropractic students Danica Holliday, Daniel Hetherington, and Tayla Johnson as well as five others who wish to remain anonymous for their contribution to data collection.
}

Authors' contributions

KJY contributed to the study design, data collection, analysis, writing of the paper, and final editing. The author(s) read and approved the final manuscript. 


\section{Funding}

The author received no funding for this project.

\section{Availability of data and materials}

Not applicable.

\section{Ethics approval and consent to participate}

Not applicable.

\section{Consent for publication}

Not applicable.

\section{Competing interests}

The authors declare that they have no competing interests.

Received: 10 January 2020 Accepted: 24 March 2020

Published online: 07 April 2020

\section{References}

1. Lee K. Toward a common language for dancer education. Res Quarterly Exercise Sport. 1995;66(1):A19.

2. Reider B. Toward a common language. Am J Sports Med. 2008;36(7):1261-2.

3. Mehra MR, Park MH, Landzberg MJ, Lala A, Waxman AB. Right heart failure: toward a common language. Pulmonary Circulatio. 2013;3(4):963-7..

4. Marschan-Piekkari R, Welch D, Welch L. Adopting a common corporate language: IHRM implications. Int J Hum Resour Manag. 1999;10(3):377-90.

5. Jette A. Toward a common language for function, disability, and health. Phys Ther. 2006;86(5):726-34

6. Vernon $\mathrm{H}$. Historical overview and update on subluxation theories. J Chiropr Humanit. 2010;17(1):22-32.

7. Budgell B. Subluxation and semantics: a corpus linguistics study. J Can Chirop Assoc. 2016;60:190

8. Strahinjevich B, Simpson JK. The schism in chiropractic through the eyes of a 1st year chiropractic student. Chiropr Man Therap. 2018;26(1):2.

9. Sandoz R. The natural history of spinal degenerative lesions. Ann Swiss Chiropr Assoc. 1989;9(1):149-92.

10. Triano JJ, McGregor M. Core and complementary chiropractic: lowering barriers to patient utilization of services. J Chiropr Humanit. 2016;23(1):1-13.

11. Branson RA. Hospital-based chiropractic integration within a large private hospital system in Minnesota: a 10-year example. J Manip Physiol Ther. 2009;32(9):740-8.

12. Saks M. Inequalities, marginality and the professions. Curr Sociol. 2015;63(6): 850-68.

13. Young KJ. Politics ahead of patients: the Battle between medical and chiropractic professional associations over the inclusion of chiropractic in the American Medicare system. Can Bull Med Hist. 2019;36(2):381-412.

14. Young KJ. A tale of specialization in 2 professions: comparing the development of radiology in chiropractic and medicine. J Chiropract Humanit. 2019:26:3-18.

15. Reid M, Barker Karen L, Lowe C. Divided by a lack of common language? - a qualitative study exploring the use of language by health professionals treating back pain. BMC Musculoskelet Disord. 2009;10(1):123.

16. Lawrence D: Toward a common language. J Manipulative Physiol Therap 1988, 11(1):1-2

17. Bryner P. Isn't it time to abandon anachronistic terminology? J Aust Chiropractor Assoc. 1987;17(2):53.

18. Millar N, Budgell B, Kwong A. Quantitative corpus-based analysis of the chiropractic literature - a pilot study. J Can Chiropr Assoc. 2011:55(1):56-60.

19. Subluxations and Dislocations. In: The Free Dictionary - Medical Dictionary; 2020. thefreedictionary.com. Accessed 24 Feb 2020.

20. Rome PL. Usage of chiropractic terminology in the literature: 296 ways to say 'subluxation': complex issues of the vertebral subluxation. Chiropr Tech. 1996:8(2):49-60

21. Homola S. Real orthopaedic subluxations versus imaginary chiropractic subluxations. Focus Altern Complement Ther. 2010;15(4):284-7.

22. Marcon AR, Murdoch B, Caulfield T. The "subluxation" issue: an analysis of chiropractic clinic websites. Arch Physiother. 2019:9(1):11.

23. Funk MF, Frisina-Deyo AJ, Mirtz TA, Perle SM. The prevalence of the term subluxation in chiropractic degree program curricula throughout the world. Chiropr Man Therap. 2018;26.
24. Mirtz TA, Perle SM. The prevalence of the term subluxation in north American English-language doctor of chiropractic programs. Chiropr Man Therap. 2011;19(1):14.

25. Palmer BJ. The Chiropractic Adjuster. Davenport: The Palmer School of Chiropractic; 1921. p. 22

26. Press CU. Adjustment. In: Cambridge English Dictionary; 2020. Accessed 24 Feb 2020

27. Adjustment. https://www.merriam-webster.com/dictionary/adjustment. Accessed 24 Feb 2020

28. Manipulate. https://www.dictionary.com/browse/manipulate. Accessed 24 Feb 2020.

29. Riekeman G. Vitalism key to contemporary health care policy: the time is now. Dynamic Chiropr. 2009;27:37.

30. Jolliot C. Vital force: an everlasting notion for the original stance of chiropractic. Chiropr J Australia. 2006;36(3):97-104.

31. Hawk C. When worldviews collide: maintaining a Vitalistic perspective in chiropractic in the postmodern era. J Chiropr Humanit. 2005:12:2-7.

32. Callender AK. The Mechanistic/Nitalistic Dualism of Chiropractic and General Systems Theory: Daniel D. Palmer and Ludwig von Bertalanffy. J Chiropr Humanit. 2007:14:1-21

33. Folk H. Vertebral vitalism: American metaphysics and the birth of chiropractic. Ph.D. Ann Arbor: Indiana University; 2006.

34. Innes SI, Leboeuf-Yde C, Walker BF. How comprehensively is evidence-based practice represented in councils on chiropractic education (CCE) educational standards: a systematic audit. Chiropr Man Therap. 2016;24(1):30.

35. Keating JC Jr. The Meanings of Innate. J Can Chiropr Assoc. 2002;46(4-10).

36. Richards D, Emmanuel E, Grace S. Duelling ontologies: might Vitalism offer balance and value? Explore. 2017:13(2):133-8.

37. Grod JP, Sikorski D, Keating JC Jr. Unsubstantiated claims in patient brochures from the largest state, provincial, and national chiropractic associations and research agencies. J Manip Physiol Ther. 2001;24(8):514-9.

38. Morgan L. Innate intelligence: its origins and problems. J Can Chiropr Assoc. 1998;42(1):35

39. Seaman D. Philosophy and science versus dogmatism in the practice of chiropractic. J Chiropr Humanit. 1998;8.

40. Hawk C. The interrelationships of wellness, public health, and chiropractic. J Chiropr Med. 2005;4(4):191-4.

41. Redwood D, Globe G. Prevention and health promotion by chiropractors. Am J Lifestyle Med. 2008;2(6):537-45.

42. Gatterman M. The patient-centred paradigm: a model for chiropractic health promotion and wellness. Chiropr J Australia. 2006;36(3):92-6.

43. Taylor DN. A theoretical basis for maintenance spinal manipulative therapy for the chiropractic profession. J Chiropr Humanit. 2011;18(1):74-85.

44. Alcantara J, Whetten A, Ohm J, Alcantara J. Ratings of perceived effectiveness, patient satisfaction and adverse events experienced by wellness chiropractic patients in a practice-based research network. Complement Ther Clin Pract. 2019:36:82-7.

45. Evans M, Perle S, Ndetan H. Chiropractic wellness on the web: the content and quality of information related to wellness and primary prevention on the Internet. Chiropr Man Therap. 2011:19(1).

46. Busse JW, Jacobs C, Ngo T, Rodine R, Torrance D, Jim J. Attitudes toward chiropractic: a survey of north American orthopaedic surgeons. Spine. 2009; 34

47. Busse JW, Janey J, Jacobs C, Ngo T, Roding R, Torrance D, Kulkami AV, Petrisor B, Drew B, Bhandari M. Attitudes towards chiropractic: an analysis of written comments from a survey of North American orthopaedic surgeons. Chiropr Man Therapies. 2011;19(25)

48. Blanchette M-A, Rivard M, Dionne CE, Cassidy JD. Chiropractors' characteristics associated with physician referrals: results from a survey of Canadian doctors of chiropractic. J Manip Physiol Ther. 2015:38(6):395-406.

49. Palmer DD. The Chiropractor's adjuster: textbook of the science, art and philosophy of chiropractic for students and practitioners. Portland: Portland Printing House Co; 1910

50. Tickel W. 'Something' you just can't get over. Chiroprc J. 2003;17(4):40

51. Borio JDC. The primordial subluxation. Chiropr J. 2010;24(11):22

52. Gay TJ. Why are you where you are? Chiropr J. 2007;21(9):31.

53. Mertz CJD. Birthing a new paradigm. Chiropr J. 2011;26(3):29.

54. Kent C. Science and innate. Chiropr J. 2001;15(6):35.

55. Epi Info. https://www.cdc.gov/epiinfo/. Accessed 10 Sept 2019.

56. Chiropractic Board of Australia. Proportion of chiropractors in states and territories. In: Chiropractic Australia: 2018; Sydney, Australia; 2018. 
57. Innes SI, Leboeuf-Yde C, Walker BF. How frequent are non-evidence-based health care beliefs in chiropractic students and do they vary across the preprofessional educational years. Chiropr Man Therap. 2018;26(1):8.

58. Kent $\mathrm{C}$. Health benefits of chiropractic care for asymptomatic persons. Chiropr J. 2004;18(9):33.

59. Pollentier A, Langworthy JM. The scope of chiropractic practice: a survey of chiropractors in the UK. Clin Chiropr. 2007;10(3):147-55.

60. Gíslason HF, Salminen JK, Sandhaugen L, Storbråten AS, Versloot R, Roug I, Newell D. The shape of chiropractic in Europe: a cross sectional survey of chiropractor's beliefs and practice. Chiropr Man Therap. 2019;27(1):16.

61. Cooperstein R, Rickard T, Claus C. Full-spine specific chiropractic technique. J Am Chiropr Assoc. 2003;40(1):20.

62. Palmer Upper Cervical Specific - HIO (Hole-in-One). http://www.upcspine. com/PDF/HIO.pdf. Accessed 15 Dec 2019.

63. Prescott D. Adjustment vs. manipulation. Chiropr J. 2001;15(10):40.

64. Herzog W, Kats M, Symons B. The effective forces transmitted by highspeed, Low-Amplitude Thoracic Manipulation. Spine. 2001;26(19):2105-10.

65. Triano JJ, Schultz AB. Loads transmitted during lumbosacral spinal manipulative therapy. Spine. 1997;22(17):1955-64.

66. Perle S. The illusion of specificity. J Am Chiropr Assoc. 2002;39(4):30

67. Reggars JW, Pollard HP. Analysis of zygapophyseal joint cracking during chiropractic manipulation. J Manip Physiol Ther. 1995;18(2):65-71.

68. Herzog W. The biomechanics of spinal manipulation. J Bodywork Movement Therap. 2010;14(3):280-6.

69. Mirtz TA, Morgan L, Wyatt LH, Greene L. An epidemiological examination of the subluxation construct using Hill's criteria of causation. Chiropr Osteopathy. 2009;17(1):13.

70. Haldeman S. Neurologic effects of the adjustment. J Manip Physiol Ther. 2000;23(2):112-4.

71. Bronfort $G$, Haas M, Evans RL, Leininger B, Triano JJ. Effectiveness of manual therapies: the UK evidence report. Chiropr Osteopat. 2010;18(3).

72. Clar C, Tsertsvadze A, Court R, Hundt GL, Clarke A, Sutcliffe P. Clinical effectiveness of manual therapy for the management of musculoskeletal and non-musculoskeletal conditions: systematic review and update of UK evidence report. Chiropractic \& manual therapies. 2014;22:12.

73. French SD, Charity MJ, Forsdike K, Gunn JM, Polus BI, Walker BF. Chiropractic observation and analysis study (COAST): providing an understanding of current chiropractic practice. Med J Aust. 2013;199.

74. Council on Chiropractic Education Australasia: Accreditation Guidelines for Chiropractic Education Programs. 2018.

75. First Contact Physiotherapy posts in General Practice: A guide for implementation. https://mskhub.org.uk/cross-cutting/first-contactpractitioner/. Accessed 24 Feb 2020.

76. Ernst E, Gilbey A. Chiropractic claims in the English-speaking world. The New Zealand Medical Journal (Online). 2010;123(1312):36-44.

77. Edwards J. Who represents the mainstream of chiropractic? In: Dynamic Chiropractic, vol. 22, 25 March 2004 edn; 2004.

78. Gliedt JA, Hawk C, Anderson M, Ahmad K, Bunn D, Cambron J, Gleberzon B, Hart J, Kizhakkeveettil A, Perle SM, et al. Chiropractic identity, role and future: a survey of north American chiropractic students. Chiropr Man Therap. 2015:23:4.

79. Costa M. Is Complementary Medicine a Valid Alternative? In: Australasian Science, vol. 34. Hawksburn: Control Publications Pty Ltd; 2013. p. 44.

80. Ernst E. Chiropractic: a critical evaluation. J Pain Symptom Manag. 2008;35.

81. Magner G. Chiropractic the Victim's perspective: Amherst: Promethius books; 1995.

82. Leboeuf-Yde C, Innes SI, Young KJ, Kawchuk GN, Hartvigsen J. Chiropractic one big unhappy family: better together or apart? Chiropr Man Therap. 2019:27(1):4.

83. Nelson CF, Lawrence DJ, Triano JJ, Bronfort G, Perle SM, Metz RD, Hegetschweiler K, LaBrot T. Chiropractic as spine care: a model for the profession. Chiropr Osteopathy. 2005;13(1):9.

84. Crawford L. Moral legitimacy: the struggle of homeopathy in the NHS Bioethics. 2016;30(2):85-95.

85. Steuter E. Contesting the rule(s) of medicine: Homeopathy's battle for legitimacy. J Can Stud. 2002;37(3):92.

86. Gleberzon BJ, Pohlman KA, Russell E. Comparison of chiropractic student lexicon at two educational institutions: a cross-sectional survey. J Can Chiropr Assoc. 2019;63(1):36-44.

87. Johnson C. Comparative effectiveness research and the chiropractic profession. J Manip Physiol Ther. 2010;33(4):243-50.
88. Veziari Y, Leach MJ, Kumar S. Barriers to the conduct and application of research in complementary and alternative medicine: a systematic review. BMC Complement Altern Med. 2017;17(1):166.

89. French SD, Downie AS, Walker BF. Low back pain: a major global problem for which the chiropractic profession needs to take more care. Chiropr Man Therap. 2018;26

90. Triano JJ, Goertz C, Weeks J, Murphy DR, Kranz KC, McClelland GC, Kopansky-Giles D, Morgan W, Nelson CF. Chiropractic in North America: toward a strategic plan for professional renewal-outcomes from the 2006 chiropractic strategic planning conference. J Manip Physiol Ther. 2010;33(5): 395-405.

91. Johnson C, Baird R, Dougherty PE, Globe G, Green BN, Haneline M, Hawk C, Injeyan HS, Killinger L, Kopansky-Giles D, et al. Chiropractic and public health: current state and future vision. J Manip Physiol Ther. 2008;31(6):397410.

92. Murphy DR, Schneider MJ, Seaman DR, Perle SM, Nelson CF. How can chiropractic become a respected mainstream profession? The example of podiatry. Chiropr Osteopathy. 2008;16(1):10.

93. Self-assessment tool launched to help practitioners and advertisers. https:// www.chiropracticboard.gov.au/News/2018-02-05-Self-assessment-toollaunched.aspx. Accessed 15 Dec 2019.

\section{Publisher's Note}

Springer Nature remains neutral with regard to jurisdictional claims in published maps and institutional affiliations.
Ready to submit your research? Choose BMC and benefit from:

- fast, convenient online submission

- thorough peer review by experienced researchers in your field

- rapid publication on acceptance

- support for research data, including large and complex data types

- gold Open Access which fosters wider collaboration and increased citations

- maximum visibility for your research: over $100 \mathrm{M}$ website views per year

At BMC, research is always in progress.

Learn more biomedcentral.com/submissions 